\title{
Las Obras Menores de Cirilo Villaverde
}

\begin{abstract}
Cirilo Villaverde nació en la plantación de caña "Santiago", en el año 1812. Como apunta A. M. Eligio de la Puente en su introducción a Dos amores, ${ }^{2}$ no pudo haber nacido en sitio más adecuado para la recopilación de datos para libros de ambiente cubano. Villaverde vivió en "Santiago" hasta los seis o siete años de edad. Alli pudo observar el trato cruel que recibían los esclavos, y según nos dice él mismo, aprovechó este conocimiento en las descripciones de escenas de crueldad en Cecilia Valdés.

Villaverde recibió una buena educación en varios colegios, obteniendo su grado de Derecho en el año de 1834. Inmediatamente comenzó a ejercer su profesión; pero se desanimó pronto y terminó abandonándola para siempre. Pasó al magisterio y enseñó en varias de las bien reputadas academias de La Habana y Matanzas. Escribió un texto sobre geografía de Cuba y otro libro titulado Los cuentos y las conversaciones.
\end{abstract}

Alrededor del año 1834 comenzó a frecuentar las tertulias literarias de Domingo del Monte. ${ }^{3}$ Aquí conoció las figuras sobresalientes del mundo literario cubano en aquella época. Tres años más tarde, en el año 1837, comenzó su carrera literaria. Exceptuada la revisión de su gran obra maestra, Cecilia Valdés, casi todas sus obras novelescas fueron escritas en el curso de los siguientes diez años.

En el año 1848 se vió envuelto en una conspiración junto con el famoso Narciso López; fué capturado por las autoridades españolas y sentenciado a muerte. Afortunadanente, pudo escapar y el siguiente año se refugió en Nueva York. En esta ciudad fué secretario 
de Narciso López, hasta la muerte de este último; fué editor y colaborador de numerosas revistas, dió clases privadas de español, fué maestro de escuela, y finalmente se dedicó, sobre todo, a ganarse la vida en un país extraño y a luchar por la causa de la independencia cubana.

Recibió el indulto político en el año 1858 y regresó a Cuba. A pesar de que compró la imprenta La Antilla y aparentemente había decidido permanecer en Cuba, se desterró voluntariamente en el año 1860. De nuevo en Nueva York, continuó su lucha por la independencia de su patria. Volvió a Cuba pocas semanas antes de morir, en el año 1894. A su regreso a Nueva York, murió en ese mismo año. Desgraciadamente, como Martí, no vivió para ver a stu país libre de la tiranía del régimen español.

Las obras políticas de Villaverde no son de la incumbencia de este trabajo. La mayor parte de ellas fué escrita en Nueva York, y muchos de sus artículos aparecieron en la revista revolucionaria $\mathrm{La}$ verdad. Tampoco nos atañen sus artículos de costumbres aunque éstos son joyas en su género. En el año 1838 había escrito ya la primera parte de Excursión a la Vuelta Abajo y la había publicado en El álbum. En 1841 aparecieron artículos como "La Habana en 1841", "Modas", "Una mudada”, "Máscaras", etc.

La primera obra de ficción de Villaverde apareció en Miscelánea de útil y agradable recreo, volumen I, agosto, 1837. Es una leyenda romántica titulada El ave muerta. También en este primer volumen aparece $L a$ peña blanca. En el volumen Ir, septiembre, 1837, aparecen dos de sus novelas cortas, El perjurio y La cueva de Taganana. En ninguna de estas historias promete mucho el futuro autor de Cecilia Valdés. Todas ellas son románticas, quiméricas y convencionales en todos sentidos. El ave muerta trata de los amores de Vicenta y Leandro. A éste lo entera su propio padre de que él y Vicenta son hermanos. Leandro huye por un año; cuando regresa, un gran fuego ha destruido la mayor parte del barrio donde había vivido. Entre los escombros encuentra un esqueleto y reconoce que es el de Vicenta, por una sortija que él le había dado. La peña blanca trata de una superstición relacionada con cierto despeñadero alumbrado por el sol, donde tan pronto como se obscurece ocurre una desgracia. La tragedia, en este caso, se basa en que el padre de la heroína ha violado a su propia hija, desapareciendo luego. Más tarde, 
cuando está felizmente casada y tiene un hijo, el padre regresa, con el objeto de asesinar al esposo; pero fracasa en su intento y muere ahorcado. El perjurio es quizás la mejor de las cuatro novelas cortas, pues en ella hay técnica dramática y más cuidado. El argumento, sin embargo, tiene poca importancia. La cueva de Taganana, aunque la más larga de todas, es la más insignificante en varios aspectos. Tanto el argumento como el desarrollo de caracteres son pobres y carecen de realidad. Es melodramática y poco convincente.

El espetón de oro y Engañar con la verdad aparecieron el siguiente año, 1838, en El álbum. La primera es algo extensa, tiene cerca de 113 páginas y realmente podría ser clasificada como "novelette". La segunda es corta y de poca trascendencia. El espetón de oro es una obra mejor que las primeras de Villaverde. Remos indica que el estilo y el desarrollo de caracteres denotan mejoría en esta obra. ${ }^{4}$ Eligio de la Puente la llama "un paso notable de avance". 5 La historia es romántica en todos sentidos. El autor, sin embargo, demuestra mayor interés en las costumbres de la época, y, a excepción de lo inverosimil del final y del desarrollo pobre del héroe, la historia es buena.

Uno de los más fascinantes cuentos de Villaverde es Lola y su periquito, que apareció en Obsequio a las damas, en 1839. El argumento y el desarrollo de caracteres tienen poca importancia; pero la historia está contada con tan gran encanto y naturalidad que resulta una promesa de éxito futuro para el autor. Otro cuento de este mismo año es Teresa. Aunque publicado en forma de libro por R. de Oliva, no es otra cosa que un cuento, pues tiene solamente cinco capítulos en 93 pequeñas páginas. ${ }^{6}$ Una cruz negra fué publicada en este mismo año, en los volúmenes 2 y 3 de La cartera cubana. Es una obra típicamente romántica en su forma y en su asunto, y recuerda novelas cortas anteriores, como La peña blanca y El ave muerta.

La primera versión de Cecilia Valdés apareció en el año 1839, en las páginas de La siempreviva. Fué publicada en dos partes o capítulos. El primero apareció en el volumen 2 de La siempreviva, pp. 75-87, y el segundo en las pp. 242-254. No es un bosquejo o croquis, como muchos han creído, de esta gran novela, sino el principio de la historia. En el mismo año, esta primera parte de la gran obra fué publicada en forma de libro. Las 246 páginas de que 
consta esta obra son pequeñas y el tipo es grande. Como dice A. M. Eligio de la Puente, la diferencia entre las dos versiones (la de $L a$ siempreviva y la del libro) es muy leve. ${ }^{7}$ La versión de La siempreviva llega hasta la página 51 de la edición en forma de libro. Hay relativamente pocos cambios. El nombre Leocadio Gamboa cambia por Leonardio Gamboa. Varios párrafos fueron omitidos y en general tiene algunas correcciones. Cuando la novela apareció completa, en el año 1882, el primer volumen, publicado con anterioridad a esta fecha, había sido grandemente alterado.

Desde el año 1842 en adelante la mayor parte de los cuentos y novelas cortas de Villaverde aparecen publicados en serie, en las páginas de El farol industrial. En 1842 publicó en este periódico El ciego y su perro, Declaración de un marinero nánfrago y Generosidad fraternal. Todas estas historias son pobres, y de muy poco valor literario. Al siguiente año pertenece La peineta calada, en la cual está el personaje Plácido. Esta historia es más larga y detallada; pero es inmaterial y poco convincente, en cuanto a argumento. En los años 1844, 1845 y 1846 aparecen La tejedora de sombreros de Yarei, Comunidad de nombres y apellidos y El misionero de Caroni. Ningunà de estas obras tienen sobresalientes méritos literarios. Al final de La tejedora de sombreros de Yarei Villaverde se excusa por haber escrito el prólogo solamente. Nos dice que ya ha escrito cuanto ha prometido y que no está en humor de continuar.

Como hemos visto, la primera novela de Villaverde fué Cecilia Valdés, publicada en 1839. El primer volumen fué lo mejor que escribió Villaverde, hasta que apareció la edición final y definitiva, en el año 1882. Descuella esta obra única y significante entre la pobreza y la prisa con que fueron escritas sus novelas y cuentos. Parece como si el autor hubiese encontrado en este tipo de novela su propio medio de expresión. Elementos históricos y costumbristas prevalecen en esta obra. Además de pintarnos en ella toda una época, hay también un argumento realista, minuciosos detalles y exactas descripciones. Se siente la seguridad con que el autor maneja el asunto. En ella todo es realidad, todo es verdad y cuidadoso artificio. $\mathrm{El}$ autor trataba de darnos historias imaginativas de otros tiempos, y debe confesarse que siempre obtuvo un mezquino éxito. Su talento no estaba orientado hacia esa dirección, ciertamente. Puede decirse que es en sus descripciones de costumbres donde Villaverde nos 
da un verdadero sentido de la realidad, y es precisamente por esto por lo que nos demuestra ser un gran novelista, un gran cuentista.

La Cecilia Valdés de 1839, sin embargo, no puede compararse con la obra maestra final del año 1882. En los años transcurridos entre estas dos fechas, Villaverde llegó a su plena madurez, como novelista del escenario cubano. Manuel de la Cruz expresa esta idea muy bien, cuando nos dice, "Las novelas de Villaverde, anteriores y posteriores al primer ensayo de Cecilia Valdés, aunque llenas de colorido local, son como ejercicios en que desarrolla sus facultades." 8 José F. Castellanos en su reciente artículo en Revista de La Habana mantiene la grandeza de la primera parte de Cecilia Valdés, edición del año 1839, pero admite que la novela completa de 1882 es superior: "Esa división temporal no resta calidades a dichas obras en lo conocido desde el primer momento: los doce capítulos de Cecilia Valdés, como la primera parte de la obra maestra de la lengua española y la del gran poema argentino (Martín Fierro), llevan ya, a manera de impronta, el genio del autor. Allí quedó también, con el estilo, el canevá en que habría de bordarse el tema en su totalidad; en fin esa primera parte permite apreciar, de modo inconfundible, como resultaría la obra terminada. Desde luego, la evolución interna del escritor, su madurez y refinamiento con el avance de los años, se manifiestan al final en un arte más depurado; es el proceso de una mejor reflexión, que antula lo intuitivo. Lo bueno siempre resultará superado por lo mejor." ’

La división de las obras de Villaverde en novelas y cuentos es arbitraria. Cecilia Valdés, en su forma final, es realmente la única novela larga compuesta por el autor. La edición de 1882 tiene alrededor de 400 largas páginas impresas en tipo pequeño. Además de Cecilia Valdés, he clasificado como novelas las siguientes: La joven de la flecha de oro, El guajiro, Dos amores y El penitente. Eligio de la Puente clasifica, como novelas: La joven de la flecha de oro, La tejedora de sombreros de Yarei, La peineta calada, Dos amores $\mathrm{y}$ El penitente. ${ }^{10}$

Como ya hemos anotado, la primera parte de Cecilia Valdés apareció en el año 1839. Fué dos años más tarde cuando el autor escribió otra novela, La joven de la flecha de oro. Esta obra es muy inferior a Cecilia Valdés. Eligio de la Puente señala, sin embargo, 
que esta obra (La joven de la flecha de oro) mereció tres ediciones y fué traducida al alemán. ${ }^{11}$

El guajiro, en el año 1842, es una novela corta de vida campesina cubana. Nos da un excelente cuadro de vida, costumbres y ambiente. El argumento es sencillo. E1 héroe es Tatao, quien está enamorado de Felicia. Tatao mata a su rival, en una riña a machete, y luego huye al interior de la isla. Hay aquí una extensa descripción de una pelea de gallos, así como de otros elementos costumbristas. La novela, o "novelette", que sería una mejor clasificación para esta obra, tiene sus raíces en Excursión a la Vuelta Abajo, cuya primera parte fué publicada en El álbum en el año 1838. Esta última obra mencionada, es un libro de viajes por esta región de Cuba, que describe la gente, su vida y costumbres, así como el paisaje.

La mejor de las obras menores de Villaverde, Dos amores, fué escrita el mismo año que El guajiro. En la primera encontramos más cuidado y atención en los detalles, que en la mayor parte de las novelas del autor. En ella hay también un poco más de elaboración en el desarrollo de personajes, que de ordinario. El carácter de la heroína, Celeste, está bastante bien desarrollado para darnos un cuadro acabado de ella. Sin embargo, el héroe, Teodoro Weber, está pobremente delineado; es obscuro e ilusorio. El argumento no es interesante ni muy original. Pérez, un hombre de negocios quien tiene tres hijas, resulta despojado de su fortuna por un empleado de confianza. Teodoro Weber, de quien se nos dice muy poco hasta el final de la obra, está enamorado de la hija mayor, Celeste, y afortunadamente puede salvar al padre de una ruina total. En su introducción a Dos amores, Eligio de la Puente señala algunos de los defectos de la obra, a pesar de lo cual la llama la mejor obra menor de Villaverde, ensalzándola en general. "Toda la complicación de la novela, en que juegan pasiones vigorosas como el amor de Weber, la ambición de don Camilo y la desgracia que abruma a Celeste; toda su trama, en fin, se desenlaza en las breves páginas del último capitu10, acumulando demasiados sucesos que debieron desarrollarse más ampliamente para preparar al lector a recibir los efectos de la pasión de Teodoro, resorte esencial de ese desenlace, que había sido dejada muy en segundo plano en todo el cuerpo de la narración, y que de repente se revela como eje y centro de su acción. Acertadamente tachó un crítico distinguido a este personaje de algo artificioso y 
teatral, porque en efecto, su intervención, providencial siempre en las situaciones más importantes de la obra, es algo que le resta valor." 12

La última de las novelas de Villaverde, anterior a la edición final de Cecilia Valdés (1882) es El penitente, 1844. Esta es una de las mejores de las obras menores del autor. La escena está situada en La Habana a mediados del siglo xvirI. Villaverde dice que fué escrita bajo la inspiración de James Fenimore Cooper; ${ }^{13}$ pero el influjo de Scott parece haber sido aún más importante en esta obra. Es una novela histórica y por lo tanto está mejor concebida que aquellas obras grandemente imaginarias de su primera época, pues como novelista de costumbres o como novelista histórico, Villaverde se destaca mejor.

Las obras menores de Cirilo Villaverde (y todas las demás, con excepción de Cecilia Valdés, puede decirse que pertenecen a este grupo) muestran a grandes intervalos la chispa del genio creador, asi como de aquél que había de escribir la más grande novela cubana. Sin embargo, frecuentemente los cuentos y novelas cortas de este gran patriota y novelista son algo mejores que los de cualquier escritor de segunda categoría, de su época. Aparentemente él no se sentía muy orgulloso de algunos de sus primeros trabajos, si hemos de juzgar por el hecho de que no pensó incluir El perjurio, La cueva de Taganana, La peña blanca y El ave muerta, en la colección de sus obras. Estos primeros trabajos de Villaverde son significativos, casi podemos decir, en cuanto se alejan del romanticismo y tienden hacia el realismo. Esto, desgraciadamente, ocurre muy raras veces. Por el contrario, muy frecuentemente sus cuentos son pobres imitaciones de los muy improbables y superimaginativos modelos en voga en aquel tiempo.

$$
\begin{aligned}
& \text { Marshall E. NunN, } \\
& \text { University of Alabama. }
\end{aligned}
$$

$\mathrm{NOTAS}$

1. Este estudio ha sido llevado a cabo mediante la ayuda del Comité de Investigaciones de la Universidad de Alabama que permitió al autor hacer averiguaciones acerca de Villaverde y su obra, en las bibliotecas de $\mathrm{La} \mathrm{Ha}$ bana, en el verano del año 1947. 
2. Dos amores, Cirilo Villaverde. Colección de Libros Cubanos, vol. 14, Cultural, p. viri, Habana, 1930, con una introducción por Eligio de la Puente.

3. Historia de la literatura cubana, Salvador Salazar y Roig. La Habana, 1929 , p. 179.

4. Historia de la literatura cubana, Juan J. Remos y Rubio, 1925. Vol. II. Pp. 170-171.

5. Op. cit., p. 20.

6. A. M. Eligio de la Puente, eminente erudito cubano, tiene las dos copias de Teresa que se conocen. Bondadosamente me permitió examinar una de ellas.

7. De una conversación en La Habana, verano de 1947.

8. Cromitos cubanos, Manuel de la Cruz. Biblioteca Calleja, Madrid, 1926, p. 170.

9. "Del Monte y Villaverde en Cecilia Valdés", por José F. Castellanos, Revista de La Habana, p. 315.

10. Op. cit., p. XxvIII.

11. Ibid., p. XxIx.

12. Ibid., p. $\mathrm{xxx}$.

13. El penitente, novela histórica cubana. Nueva York, 1889, prólogo, p. vII. 